\title{
Developing Critical Reading Skills through Stylistic Analysis in Integrated College English Classroom* $^{*}$
}

\author{
Kang Liu \\ Sichuan University of Arts and Science, Dazhou, Sichuan, China
}

\begin{abstract}
Reading is a dynamic and interactive process between the reader and the writer, which goes beyond the literal study of the text. It requires readers to actively engage in analysis, judgment and evaluation of information. However, integrated college English classes focus more on students' language proficiency and restrain students' critical competence. The deficiency of critical thinking skills and disposition defects the students' power of creativity and innovation competence. So it is obligated for college English teachers to improve critical awareness and employ stylistic analysis method to help students to develop critical reading skills, building up students' ability to predict, reason, analyze and evaluate the reading materials.
\end{abstract}

Index Terms - college English teaching, critical reading, stylistic analysis

\section{INTRODUCTION}

In the $21^{\text {st }}$ century, with the advanced development of computer science, people are more and more widely immersed in a vast sea of information, so it is a must to learn to select, analyze, judge and assess what information we need in the personal, professional or academic lives. That's to say, we should learn to read actively and critically rather than passively absorb the reading information. Reading critically or critical reading is a high-level reading activity between readers and writers which entails the ability to read with analysis and judgment, it analyses not only what a text says but also how it says it $(\mathrm{Li}, 2010)$. A writer writes to assure the readers to accept the ideas in the text, and the readers have to read and decide whether to follow the writer's arguments or what to accept. In the newly-revised Guidelines on College English Teaching, it is required that students read to distinguish opinions from facts, understand the implied meaning and main idea of the text, grasp the logical structure and comprehensively analyze the text to speak up one's own opinions (Ministry of Education, 2017). According to the Guidelines, reading goes beyond the literal study of the text, it involves carefully considering and evaluating the materials, identifying the strengths or weakness and implications of the articles, which is exactly what critical reading demands. Critical reading plays a vital role in developing students' critical thinking abilities. However, traditional Chinese English teaching classroom rarely encouraged cultivating students' critical thinking (O'Sullivan \& Lin, 2010). Take college English reading for example, teachers remain in the dominating position, controlling much of the class to spoon-feed knowledge and culture or to explain and train reading skills. Students passively follow the teacher in the reading classroom; they are mainly trained to improve their language skills - to enlarge their list of vocabulary, broaden their cultural eyesight or improve comprehension abilities (Xu, 2011). Such traditional lecturing and reading activities are not very helpful in fostering students' critical thinking proficiency. As a result, the students usually accept the information of a reading text without training of analyzing, questioning, distinguishing or criticizing. Many students can't express points of view of their own after reading a text. Such "reading crisis" severely restrains qualified personnel production (Zhang, 2012). This paper discusses the connotation of being critical and claims to cultivate critical reading skills by using stylistic analysis method in college English reading classroom, illustrated with a reading lesson "How deep is your love?" from New Century College English Integrated Course (Book Three) by Qing Xiubai as a case study.

\section{Connotation of Critical Reading}

\section{A. Definition of Being Critical}

Many people equate the idea of being critical with criticism of what other people are doing, or finding faults of something. Etymologically, the English word "critical" derives from two Greek roots "kriticos" meaning evaluation and "kriterio" meaning criteria. So the true meaning of "critical" is to make an evaluation or a judgment according to some principle. In the American Heritage Dictionary of English Language, the definition of the word critical is to be characterized with exact, careful evaluation and judgment. In Longman Dictionary of Contemporary English, "critical"

\footnotetext{
* Funded by Education \&Teaching Reform Programme of Sichuan University of Arts and Science in 2018 "The Application-oriental Assessment System of Level-based College English Teaching" (Program No: 2017JY12).
} 
is defined as providing careful and fair judgment of something. From above, we can see being critical doesn't necessarily connote negative meanings or find faults, it means "using careful evaluation, sound judgment and reasoning power" (Milan, 1995, P.218). The critical ability is highly valued as a kind of literacy. In England, master degrees are only awarded to students who have demonstrated a critical awareness of current problems and have conceptual understanding that enables the students to evaluate critically current researches (Poulson \& Wallace, 2004)

\section{B. Essence of Critical Reading}

The ability of being critical in reading activity is termed as critical reading, which is contrasted to literal reading. Academically, many scholars have given definitions to critical reading. Hafner defines critical reading as "a thinking process that is improved by way of using language more constructively and clarifying concepts through discussion and questioning" (Hafner, 1974, P.40). Maker \& Lenier argue that critical reading is "the process of making judgments about what you read and deciding what to believe and what not to believe" (Maker \& Lenier, 1986, P.138). Relatively speaking, Priozzi gives a more clear definition as follows:

Critical reading is a high-level comprehension of written material requiring interpretation and evaluation skills that enable readers to separate important from unimportant information, distinguish between facts and opinions and determine a writer's purpose and tone. It also entails using reference to go beyond what is stated explicitly, filling in information gap and coming to logical conclusion (Priozzi, 2003, P.325).

Critical reading is a sophisticated activity, including psychological, linguistic and sociological aspects, it is an ongoing interactive process in which the reader actively produces meaning through a set of mental processes from the text and the author (Shihab, 2011). To sum up, critical reading is a purposeful and reflective process of comprehending, analyzing, judging and evaluating the written materials so as to respond intelligently to the writer. It is considered to be an indispensable ability of literacy as equally important as writing and arithmetic. During the course of reading, a critical reader needs to differentiate facts from opinions; to understand the literal or implied meanings and the narrator's tone; to find the connections between the events or actions; to detect an inferential relationship from the details observed; to make moral reasoning and fair-grounded judgments. In a sense, critical reading is to exercise what the experts term explanation, analysis, synthesis, argumentation, evaluation, problem-solving, logical reasoning and application (Fahim \& Sa'eepour, 2011).

Critical reading must be based on literal reading. In literal reading, the reader only needs to read the lines, locating information, using context clues to supply meaning or identifying the explicitly stated relationships and organizational patterns. Different from the literal comprehension, reading critically requires the reader to interact with the writer, identifying, analyzing, detecting and comparing as he thinks along with the writer about the ideas in the text. So literal reading is the threshold to critical reading $(\mathrm{Li}, 2010)$.

\section{Applying Stylistic Analysis to Developing Critical Reading Skills}

College English is a course of liberal education, which should focus on concepts of holistic education--the harmonious unity of knowledge, skills and personhood, and critical ability is one of the key ingredients of holistic education (Wen, 2016). But in most college English integrated classes, more attention is paid to explaining of words, translating of sentences or analyzing of grammatical structures, yet little concern is shown to the logic link between the paragraphs or the theme of the text course. Such teacher-centered teaching model only helps students to get literal understanding of the language elements. As we see, language is a sign to record social practice and human conduct. Most frequently, Human's ideology is implied within the language forms. Only literal reading is not enough for us to get to know the essence of the text, we must read to find the information that is not explicitly stated and try to compare the information with our knowledge in order to get a valued response to the text. This is a task of inferential reading, critical reading and appreciative reading. Such three types of reading comprehension are basically grounded on stylistic analysis of the text.

\section{A. What Is Stylistic Analysis?}

Stylistics is a branch of linguistics, which is simply defined as study of the use of languages (Leech \& Short, 1981). Stylistic analysis is to explore language, it mainly involves the varieties of language of a text, namely, the way words are pronounced, the way words combine with other words to form phrase and sentences, the meaning of words and sentences or the meaning of language in context, etc. In short, stylistic analysis is concerned with examining or analyzing various phenomena of the vocabulary, grammar and phonetics from the point of their stylistic functions for delivering thought, attitudes and emotions in various situations of communication. So stylistic analysis is a useful method of interpreting texts. With that, you go beyond the surface content to understand the text much more deeply and critically. Since the levels of language are various, stylistic analysis is therefore muti-dimensional, it can be done from different perspectives of phonology, graphology, syntax, lexicology, semantics and so on. Here in this paper, three levels are mainly discussed.

\section{B. Critically Reading through Stylistic Analysis}

Reading through stylistic analysis, we attempt to explain how the words, grammar or figures of speech of a text 
create the feelings and responses that we gain while we are reading. Such subjective impression of the text originates from the objective study of the features of the language. Necessarily, stylistic analysis is an activity exactly associated with a specific text. This paper chooses the text How Deep Is Your Love from New Century College English Integrated Course -Book Three (Qing, 2014) as a case study. The author of this text discusses love of different depths from her own experience and contrasts two types of love relationships of the young generation and their parents' generation, finally the author advises the young people to learn the essence of love and find ways to develop relationship of true love.

1 From the lexical perspective

Word is the basic unit of language, which is used to convey facts or opinions. While reading, we need to pay close attention to features of the vocabulary. Is the vocabulary formal or colloquial? Descriptive or evaluative? Simple or complex? Especially, much importance is attached to the emotive effects of the words because the emotive effects of words usually indicate the author's opinions, attitude or feelings. Additionally, most words in written texts possess two levels of meaning. The first and the easiest to analyze is the literal or descriptive meaning of words. However, beyond dictionary definitions, words communicate or connote emotions, biases, attitudes, and perspectives. In many texts, especially those aimed for persuasion, criticism, suggestion etc., authors often deliberately use connotative language to appeal to emotions in order to make their ideas acceptable and believable. They are aware of the truth that it is not always what we say but how we say it that influences people. So effectively analyzing a text involves learning to interpret what is implied or suggested just as well as what is explicitly stated from the lexical perspective. Look at this passage below:

I am amazed when I hear stories of school kids bragging about the number of physical relationships they have had. I am horrified to learn that girls barely eighteen have already been in and out of seven to eight "hook ups".

(Adapted From the text How deep is your love by Mansi Bhatia in New Century College English Integrated CourseBook Three. )

This paragraph shows how the author feels about the way the school kids and the teenage girls treat love. Although the author doesn't state out her opinion directly, however, the words "amazed", "horrified", "barely"and "already" give a signal of negative emotive effects, implying the young boys and girls are too hasty and frivolous in love. We can judge that the author absolutely disapproves such kind of love affairs. Comparatively, the author's parents' generation handle love and relationship like this:

Our parents' generation was fed lavishly with ideals. It was an era of constraints, restraints, respect, admiration, and plenty of romance. The long skirts, the quiet and unpretentious looks, the curled long hair, the calmness, the shy glance - these are all so frequently remindful of a bygone era. An age when the distance between the sexes somehow managed to help preserve the holiness of love and relationships.

(Adapted From the text How deep is your love by Mansi Bhatia in New Century College English Integrated CourseBook Three. )

According to the above paragraph, the older generation handled love and relationship with more "constraints", "restraints", "respect", "admiration", and plenty of "romance". They tended to preserve the "holiness" of love and relationship. The words in the quotation marks contain six or above six letters, or three or above three syllables. Such words are called BIG WORDS, which are very formal and serious in tone. Here, the author uses these big words to denote that her parents' generation take serious and holy attitudes to love, which makes the author feel that "these are all frequently remindful of a bygone era". The words "remindful" and "bygone" show that the author sounds disappointed with the young people's hasty behavior in love today, and that she is longing for the traditional love of the old generation. It seems to be a pity for the author that the traditional way of handling love relationship is now gone forever.

2 From the syntactic perspective

A sentence is orderly arrangement of words, it is a grammatical unit of language. Syntactic analysis is about to analyze the types and complexity of the sentence, the clause structure, the verb tenses or the phrase types as well as word class. These syntactic features can usually express the writer's unstated feelings and points of view.

2.1 Verb tense

The tense of a verb tells when a person does something or when something exists or happens, it expresses more than the time of the movements or situations of the predicate verbs, it also indicates some phenomena and the writer's attitudes towards the phenomena.

The author of this paper conducts a statistics of tense of main verbs in the text How deep is your love. Usually, a sentence is marked with a full stop, a question mark or exclamatory mark, so there are 57 sentences in all (not including the lines of the poem at the very beginning) in this text. Here is a table of the usages of verb tense in the text How deep is your love.

\begin{tabular}{|l|c|c|c|}
\hline Verb tense & The simple present tense & The present perfect tense & The simple past tense \\
\hline Frequency & 37 & 4 & 16 \\
\hline
\end{tabular}

The author of the text applies the present tense when narrating the young people's practice to love relationship. From the above statistics, the total of the present tense is forty-one times, with seventy-two percent, which is a big percentage. 
With the wide application of present tense in the text, the author, Mansi Mhatia, intends to show that most of young people today have reshaped different opinions on love relationship, compared with the old generations. It is universally believed that young people treat love with frivolous acts. Although such phenomenon is common, the author shows her disapproval of it.

2.2 Sentence type

Sentence types can be differently categorized according to different criteria. In terms of sentence length, the sentence can be classified into long sentence and short sentence; in terms of complexity, it is divided into simple sentence and multiple sentence; in terms of function, it is grouped into four kinds: declarative, interrogative, imperative and exclamatory. Different sentence types can also represent some implied meaning. For instance, the short sentences are usually emphatic, and they are characteristic of brevity and force, while the long sentences give out the impression of formality and solemnity. Look at the following example:

This is exactly what reading should be like, but in school, reading is not always an exciting, joyous adventure. Find something, dive into it, take the good parts, skip the bad parts, get what you can out of it, go on to something else. Why should we insist that every child should read the same book and get the same scrap of "understanding" out of it?

(Adapted from the text Learning to read By John Holt in New Century College English Integrated Course-Book One.)

The author, John Holt, believed reading should always be an exciting and joyous adventure, he advocated that teachers should get rid of the students' dislike and fear of books so that the children would love books and feel more confident about their reading. So in the above paragraph when the author suggested the ways of reading, he used many short imperative sentences, "find something", "dive into it", "take the good parts", "skip the bad parts", "get what you can out of it" and "go on to something else". These short sentences sound light and rhythmical, they can bring us reading pleasure, which fits perfectly with the central idea of the text. Therefore, the choice of sentence type is not made at random, it must be in accordance with the expression of the theme.

3 From the rhetorical perspective

The rhetorical device is a technique to convey a meaning with the goal of persuading readers into considering a topic from a different perspective. Rhetorical devices can not only beautify the language, but also evoke an emotional response, generating spiritual significance as well as persuasion. So analysis of the rhetorical devices can encourage us to read and think critically about the text. In the text How deep is your love, the author uses such rhetorical devices to get desired results.

3.1 Simile

A simile is a figure of speech that aims to make a comparison between two different things, showing similarities with the help of the words "like" or "as". Therefore, it is a direct comparison. In writing, similes can be used to vividly express deeper meaning, conveying complexity or adding greater significance to his text. In the text How deep is your love, the author thought her early love experience to be "harmless puppy loves that are as brief as soap bubbles". "Puppy loves" means love happening to people who are too young to understand the essence of love. "Soap bubbles" are colorful, but easily broken. Here the author uses a simile to compare her puppy loves to soap bubbles, both share the same characteristics that they exist in a short time and produce no lasting influence. So the true meaning the author wants to express is that her early love affair is silly and brief, not true love.

3.2 Metaphor

A metaphor is a figure of speech in which the speaker or writer uses a word or phrase denoting one kind of object or action to take place of another so as to suggest a likeness or analogy between them. A metaphor is an implied comparison, in contrast to the explicit comparison of the simile, which uses like or as. In the daily life or in a piece of literature, appropriate metaphors can sharpen our imaginations to comprehend what is abstractly stated.

In the sentence "Love was a magnificent building I had built on the foundation of friendship. It took time to blossom.", "magnificent building" is used to imply that love should be developed in the way we construct a great building which doesn't do without a strong foundation. Like a building, love should also base on something. "To blossom" is another metaphor, which implies that love can be as beautiful as a flower, needing time and nutrition so as to grow well. The author uses the mechanism of metaphor to imply that true love demands a lot of understanding, loads of sharing and caring as basis. Love means unselfishness, a willingness to sacrifice one's own wishes and interests for those of the other part.

The same rhetorical device is used in the sentence "What about giving ourselves, and others, time and space to forge relationship?". "To forge" literally means "to form something, such as metal by heating and hammering". The author implies that love relationships, like iron needing tempering, require time to develop stronger mutual affection before they become as solid and strong as steel.

3.3 Parallelism

Parallelism is a grammatical term for arranging words with syntactically accurate structure. Parallelism in literature is using equivalent or identical syntactic constructions in corresponding clauses and phrases. Parallel structure is essential to accurate grammatical structure, it can help to improve coherence and consistency, making readers deeply impressed. Here are examples of parallelism in the same above text:

There is more of closeness and less of intimacy. There is more of passion and less of emotion. There is more of 
acquiring and less of sharing. There is more of opportunism and less of selflessness. In short, there is more of ME and less of US.

(Adapted from How deep is your love by Mansi Bhatia in New Century College English Integrated Course-Book Three.)

In the above paragraph, with the same five sentence structures and repeated contrasts between "more..." and "less...", parallelism is used to state that the young people enter the relationships under the pressure of lust, and that they treat love in a more self-centered way, only concerned with their own feelings and interests in an affair, forgetting that love also needs sharing and giving. With the parallel structure, emphasis is achieved to denote the author's disapproval of the way young people handle love relationship with the opposite sex. Consequently, the author puts forward his opinions on love, using parallel structures of seven sentences introduced by "what about".

What about gifting our object of affection, our time, our company, our support, our friendship? What about setting priorities in our lives and focusing on each with sincerity? What about trying to be self-sufficient emotionally before letting ourselves loose? What about giving ourselves, and others, time and space to forge relationships? What about working towards meaningful and lasting friendships? What about honoring our commitments? What about channeling our energies and emotions towards building lifelong bonds rather than wasting them on seasonal relationships?

(Adapted from How deep is your love by Mansi Bhatia in New Century College English Integrated Course-Book Three.)

Parallelism in this paragraph is in the form of rhetorical questions. The author, Mansi Bhatia presents his opinions on developing true love relationship with seven rhetorical questions introduced by "what about", which ask for no answers. Parallel rhetorical questions sound more persuasive and acceptable than declarative statements. With such device of parallel structure, the author skillfully persuades the young people into learning the essence of love and find ways to develop relationships into lifelong bonds.

From the above case study, stylistic analysis not only brings a clear understanding of what the text means, but also uncovers how the text means and why the text is valued as it is. So stylistic analysis is an access to critical reading as well as a process of critical reading activity.

\section{SUMMARY}

Reading falls into literal comprehension, inferential comprehension, critical comprehension and appreciative comprehension (Richards \& Platt, 2008). Literal comprehension is reading in order to understand, remember or recall what the word means or what the text is about, which is a basic and cognitive level of reading activity. Critical comprehension is analyzing, synthesizing and evaluating the text in order to acquire emotional experience and reasonable judgment of value. Such experience and assessment is achieved on the basis of language media, including the sound of language, the shape of language, the way how words combine with other words to form sentences, the meaning of language in context, the rhetorical device in the discourse etc.. So integrated college English teachers and learners are suggested to attach much more importance to close reading, doing stylistic analysis from different levels of text language to improve language awareness and critical reading skills. Of course, written response is also proposed because writing is the essential ingredient in critical thinking instruction (Wade, 1995). After comprehending and evaluating the text, it is a good way to write summaries, commentaries or reading journals, which equally benefits students' critical reading and thinking skills.

\section{REFERENCES}

[1] Fahim, M. \& Sa'eepour, M. (2011). The Impact of Teaching Critical Thinking Skills on Reading Comprehension of Iranian EFL Learners. Journal of Language Teaching and Research, 2, 867-874.

[2] Hafner, L. E. (1974). Improving Reading in Middle and Secondary Schools. New York: Macmillan Publishing Co., Inc.

[3] Jack, C. R. John, P. \& Heidi, P. (2000). Longman Dictionary of Language Teaching \& Applied Linguistics. Beijing: Foreign Language Teaching \& Research Press.

[4] Leech, G. N. \& Short, M. (1981). Style in Fiction. London: Longman.

[5] Li, H. J. (2010). Developing a Hierarchical Framework of Critical Reading Proficiency. Chinese Journal of Applied Linguistics (Bimonthly), Vol. 33, No.6, 40-46.

[6] Maker, J. \& Lenier, M. (1986). College Reading (2 $2^{\text {nd }}$ ed.). Belmont: Wadsworth Publishing Company.

[7] Milan, D. (1995). Developing Reading Skills. New York: McGraw_Hill, Inc. P. 218.

[8] Ministry of Education. (2017). Guidelines on College English Teaching. Beijing: Foreign Language Teaching and Research Press.

[9] O’Sullivan, M. \& Lin, Y. G. (2010). Critical Thinking and Chinese International Students: An East-West Dialogue. Journal of Contemporary Issues in Education, 5, 53-73.

[10] Pirozzi, R. (2003). Critical Reading, Critical Thinking (2 ${ }^{\text {nd }}$ ed.). New York: Longman.

[11] Poulson, L. \& Wallace, M. (2004). Designing and Writing about Research: Developing a critical frame of mind. London: SAGE Publications.

[12] Qing, X. B. (2014). New Century College English Integrated Course (Book Three). Shanghai: Shanghai Foreign Language Education Press.

[13] Shihab, I. M. (2011). Reading as Critical Thinking. Asian Social Science, 7, 209-218. 
[14] Wade, C. (1995). Using Writing to Develop and Assess Critical Thinking. Teaching of Psychology, 24, 24-28.

[15] Wen, X. (2016). Holistic education and training of English majors. Journal of Northeast Normal University (Philosophy and Social Science), 281(3), 118-120.

[16] Xu, J. (2011). The Application of critical thinking in teaching English reading. Theory and Practice in Language Studies, 1, 136-141.

[17] Zhang, S. J. (2012). Reading and Writing Crisis, the Biggest Challenge for English Majors. Foreign Language Learning Theory and Practice, 2, 1-5.

Kang Liu, is currently a lecture of English at School of Foreign Languages, Sichuan University of Arts and Science, China. As a visiting scholar, he studied in Eastern Mennonite University in America from September, 2010 to January, 2011. His research interests cover English teaching, culture of English-speaking countries. 